\title{
Identification of Potential Therapeutic Targets Among CXC Chemokines in Breast Tumor Microenvironment Using Integrative Bioinformatics Analysis
}

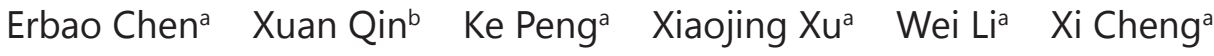 \\ Cheng Tang $^{\mathrm{a}}$ Yuehong Cui ${ }^{\mathrm{a}}$ Zhiming Wang ${ }^{\mathrm{a}}$ Tianshu Liu ${ }^{\mathrm{a}}$ \\ aDepartment of Medical Oncology, Zhongshan Hospital, Fudan University, Shanghai, bSchool of \\ Chemical Biology and Biotechnology, Shenzhen Graduate School of Peking University, Shenzhen, China
}

\section{Key Words}

Chemokine $\cdot$ Breast cancer $\bullet$ Tumor microenvironment $\bullet$ Prognosis

\begin{abstract}
Background/Aims: Breast cancer is a common cause of cancer mortality throughout the world. The cross-talk between cancer cells and interstitial cells exerts significant effects on neoplasia and tumor development and is modulated in part by chemokines. CXC is one of four chemokine families involved in mediating survival, angiogenesis, and immunosensitization by chemoattracting leukocytes, and it incentivizes tumor cell growth, invasion and metastasis in the tumor microenvironment. However, the differential expression profiles and prognostic values of these chemokines remains to be elucidated. Methods: In this study, we compared transcriptional CXC chemokines and survival data of patients with breast carcinoma (BC) using the ONCOMINE dataset, Kaplan-Meier Plotter, TCGA and CBioPortal. Results: We discovered increased mRNA levels for CXCL8/10/11/16/17, whereas mRNA expression of CXCL1/2/3/4/5/6/7/12/14 was lower in BC patients compared to non-tumor tissues. KaplanMeier plots revealed that high mRNA levels of CXCL1/2/3/4/5/6/7/12/14 correlate with relapse-free survival (RFS) in all types of BC patients. Conversely, high CXCL8/10/11 predicted worse RFS in BC patients. Significantly, high transcription levels of CXCL9/12/13/14 conferred an overall survival (OS) advantage in BC patients, while high levels of CXCL8 demonstrated shorter OS in all BC sufferers. Conclusions: Integrative bioinformatics analysis suggests that CXCL8/12/14 are potential suitable targets for precision therapy in BC patients compared to other CXC chemokines.
\end{abstract}

B. Chen, X. Qin and K. Peng contributed equally to this work. 


\section{Cellular Physiology Cell Physiol Biochem 2018;45:1731-1746 and Biochemistry Published online: March 01, 2018 \begin{tabular}{l|l} 
DOI: 10.1159/000487782 & $\begin{array}{l}\text { C } 2018 \text { The Author(s). Published by S. Karger AG, Basel } \\
\text { www.karger.com/cpb }\end{array}$
\end{tabular} \\ Chen et al.: Therapeutic Targets Among CXCLs in TME}

\section{Introduction}

Breast cancer (BC), the most prevalent cancer in the world among women, presents nearly 1.7 million new cases worldwide each year [1]. Due to remarkable advances made in diagnosis and therapy, the survival rates for $\mathrm{BC}$ patients have increased in regions with adequate medical research. In contrast, the efficacy of precision target therapies for $\mathrm{BC}$ remains stagnant due to multifaceted gene dysregulation and complex molecular mechanisms that involve multiple pathological and molecular subtypes. One of the classic molecular subtypes relies on expression of estrogen receptor (ER), progesterone receptor (PR) and epidermal growth factor receptor 2 (HER2) to provide important clinical and predictive therapeutic information [2,3]. Researchers and clinicians are increasingly regarding cancer as an imbalance between normal cells and the immune system. The cross-talk between cancer cells and immune cells is a pivotal part of cancer growth, metastasis, and treatment effects [4]. Hence, identifying novel biomarkers in the immune system for BC is urgent and required to achieve the goal of individualized treatment.

Chemokines are a family of low molecular weight, secreted signaling proteins well known for modulating immune cell trafficking and stromal cell development. Chemokines are classified into diverse groups according to their structural and behavioral characteristics. All chemokines are divided into four main classes based on their cysteine (C) residue sequence: the CXC chemokines, the CC chemokines, the $\mathrm{C}$ chemokines and CX3C chemokines, in which $\mathrm{X}$ represents any amino acid [5]. The nearly 50 chemokines identified in humans are divided into two differential functional groups: inflammatory chemokines and homeostatic chemokines. Inflammatory chemokines are usually induced by harmful stimulants, such as infections or cell damage, while homeostatic chemokines are constitutively expressed in normal immune network regulation. Aside from being known for mediating chemotaxis, most chemokines exhibit various additional functions related to cell proliferation and survival and to the stimulation or inhibition of angiogenesis.

Seventeen CXC chemokines have been described in humans. Interestingly, CXC chemokines can be further separated based on the presence or absence of an ELR (Glu, Leu, Arg) motif, which is situated before the first conserved cysteine residue. Almost all ELR ${ }^{+}$ CXC chemokines are considered contributors to neutrophil aggregation and/or angiogenesis $[6,7]$. In contrast, ELR CXC chemokines attract lymphocytes, such as T cells, B cells, and natural killer (NK) cells $[8,9]$. Although several studies have uncovered a general profile for CXC chemokines in $\mathrm{BC}$, identifying suitable targets for precision therapy remains a challenge that urgently needs attention in this field. In the present study, we implemented a deep bioinformatics analysis of the clinicopathological and survival data as it relates to CXC chemokines in patients with BC based on several large public databases in order to illustrate their prognostic and potential therapeutic value in cancer treatment.

\section{Materials and Methods}

\section{ONCOMINE data-mining analysis}

ONCOMINE (www.oncomine.org), an online web-based cancer database for RNA and DNA sequences, was used to facilitate data-mining the transcriptional expression of CXC chemokines in 20 types of cancer [10]. Transcriptional expression of CXCL chemokines in cancer samples were in compared with those in normal individuals using Student's t-test. Statistically significant values and fold change were demarcated as $\mathrm{p}<0.05$ and 2 , respectively.

bcGenExMiner $v 4.0$

Breast Cancer Gene-Expression Miner v4.0 (bcGenExMiner v4.0) is a statistical mining tool of 36 noted genomic datasets and three classical mining functions: expression, prognosis, and correlation [11, 12]. Expression data was updated in March 2016 and compares production of a particular gene with clinical 


\section{Cellular Physiology Cell Physiol Biochem 2018;45:1731-1746 \begin{tabular}{l|l} 
and Biochemistry POI: 10.1159/000487782 & $\begin{array}{l}\text { (c) } 2018 \text { The Author(s). Published by S. Karger AG, Basel } \\
\text { www.karger.com/cpb }\end{array}$
\end{tabular}}

Chen et al.: Therapeutic Targets Among CXCLs in TME

parameters such as age, ER, PR, HER2, and so on. The prognosis module calculates the prognostic value of target genes in $\mathrm{BC}$ and offers potential novel prognostic markers.

\section{Kaplan-Meier Plotter}

The prognostic value of CXC chemokine mRNA transcription level was measured using an online open database, the Kaplan-Meier Plotter (www.kmplot.com) [13], which consists of gene expression profiles and survival information for 1, 809 BC patients. To evaluate the relapse-free survival (RFS) of patients with BC, individuals were separated into two groups based on median gene expression (high vs. low) and validated by K-M survival curves. The mean value of each CXC chemokine's multiple probes was determined to generate $\mathrm{K}-\mathrm{M}$ survival curves, and the number-at-risk is displayed below the curves.

\section{TCGA data and cBioPortal}

The Cancer Genome Atlas (TCGA) contains gene expression data obtained by sequencing and has accurate clinical and pathological data on many cancers [14]. The cBioPortal (www. cbioportal.org) is an open-access data set for exploring multiple cancer genes. The BC dataset contains data from 1105 cases, with pathologic diagnosis chosen by cBioPortal for further analyses of CXC chemokines $[15,16]$.

\section{Results}

\section{Dysregulated expression of CXC chemokines in patients with $B C$}

SixteenCXCchemokineswereidentified using theONCOMINEdatabase, excludingCXCL15. As shown in Fig. 1, we first measured expression of CXC chemokines in 20 types of cancer and compared those to normal individuals. The mRNA expression of CXCL8/10/11/16/17 was significantly up-regulated in $\mathrm{BC}$ samples in multiple datasets. According to the Curtis dataset, CXCL8 overexpression was observed in a few types of BC compared with normal tissues, with a fold change in ductal BC of 2.593 [17], while Richardson reported ductal BC as having a CXCL8 fold change=4.856 (Table 1) [18]. Overexpression of CXCL10 has also been reported in all types of $\mathrm{BC}$ compared with normal breast tissue, including mucinous $\mathrm{BC}$ with

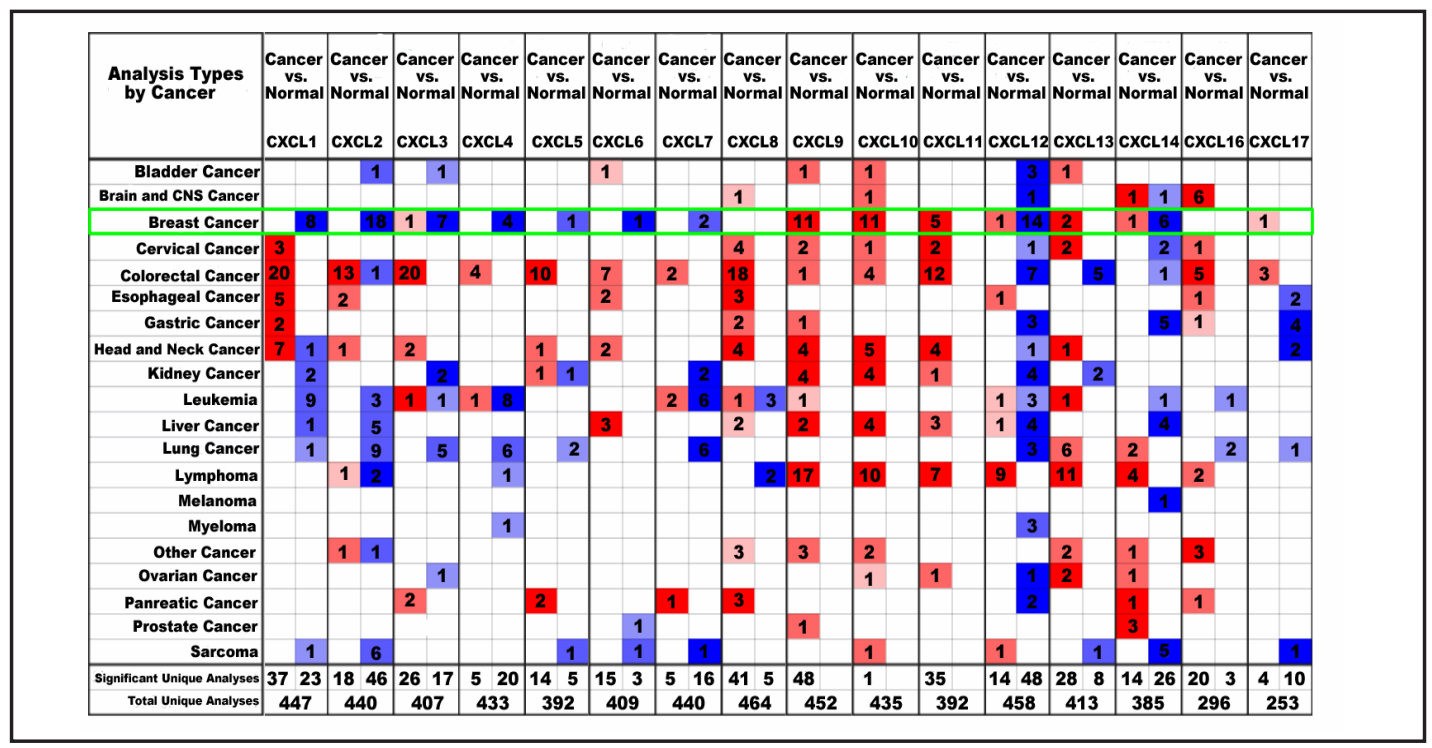

Fig. 1. Transcriptional levels of CXC chemokines in different types of cancers with the threshold of P-value $\leq 1 \mathrm{E}-4$, Fold Change $\geq 2$, and Gene Rank $\geq$ Top 10\%. This information was attained from ONCOMINE and indicates the numbers of datasets with statistically significant $(\mathrm{p}<0.05)$ mRNA high-expression (Red) or low-expression (Blue) of CXC chemokines (different types of cancer vs. corresponding normal tissue). Cell color was decided by the best gene rank percentile for the analyses within the cell, and the gene rank was analyzed by percentile of target genes in the top of all genes measured by each study. 
fold change 2.166, mixed lobular and ductal BC with fold change 2.086, invasive lobular BC with fold change 2.383 , and invasive $\mathrm{BC}$ with fold change 3.009 , according to the TCGA dataset. Data from Curtis report CXCL10 levels in medullary BC with fold change $=15.564$, ductal BC with fold change $=4.231$, and invasive $\mathrm{BC}$ with fold change $=4.398$. In different datasets for CXCL10, we observed invasive ductal BC having a fold change $=5.002$ compared with normal breast reported by Curtis, and a similar trend was found by Karnoub (5.072) [19], Turashvili (4.877) [20], and Ma 4 (4.915) datasets [21].

CXCL11 is another chemokine of interest in the CXC family with respect to BC. mRNA expression of CXCL11 was found to be upregulated in most types of $\mathrm{BC}$ compared to normal breast tissue. Transcriptional levels of CXCL11 in invasive ductal BC exhibited fold change $=10.712 \quad$ [19], while TCGA and Radvanyi reported slightly lower fold changes (5.867 and 7.089, respectively) [22]. Both sources report markedly increased expression of CXCL16 in invasive lobular $\mathrm{BC}$ and invasive ductal BC, with fold changes $=2.369$ and 2.225, respectively. However, only Finak reported that high expression of CXCL17 was associated with invasive BC, in contrast to normal tissue (fold change $=2.257$ ) [23].

Increased expression of CXCL2/12/13/14 and reduced expression of CXCL8 are correlated with preferable RFS or OS in BC patients

We separated all types of $\mathrm{BC}$ patients into one of two groups for chemokine expression (high vs low) based on median expression values for each chemokine across all samples. Fig. 1 presents transcription levels of CXC chemokines in different types of cancers with
Table 1. The significant changes of CXC-chemokines expression in transcription levels between different types of $\mathrm{BC}$ and breast tissues (ONCOMINE database)

\begin{tabular}{|c|c|c|c|c|c|}
\hline & Type & Fold change & P value & $\mathrm{t}$-test & REF \\
\hline \multirow[t]{4}{*}{ CXCL8 } & Ductal BC & 2.593 & 0.028 & 2.184 & Curtis [17] \\
\hline & Ductal bc in situ epithelia & 3.649 & 0.012 & 2.619 & Ma [21] \\
\hline & Ductal BC & 4.856 & $3.71 \mathrm{E}-4$ & 4.284 & Richardson[18] \\
\hline & Intraductal cribriform B adenocarcinoma & 3.313 & 0.047 & 2.736 & TCGA \\
\hline \multirow[t]{16}{*}{ CXCL10 } & Ductal BC & 19.021 & $8.00 \mathrm{e}-12$ & 9.558 & Richardson[18] \\
\hline & Mucinous BC & 2.166 & $1.71 \mathrm{E}-7$ & 7.611 & TCGA \\
\hline & Mixed lobular and ductal BC & 2.086 & $1.14 \mathrm{E}-5$ & 5.838 & TCGA \\
\hline & Invasive lobular BC & 2.383 & $3.52 \mathrm{E}-12$ & 7.870 & TCGA \\
\hline & Invasive $\mathrm{BC}$ & 3.009 & $5.77 \mathrm{E}-17$ & 9.973 & TCGA \\
\hline & Medullary BC & 15.564 & $9.43 \mathrm{E}-14$ & 11.593 & Curtis [17] \\
\hline & Ductal BC & 4.231 & $7.79 \mathrm{E}-5$ & 5.891 & Curtis [17] \\
\hline & Invasive ductal BC & 5.022 & $4.40 \mathrm{E}-71$ & 26.711 & Curtis [17] \\
\hline & Invasive BC & 4.398 & $8.97 \mathrm{E}-6$ & 5.467 & Curtis [17] \\
\hline & Invasive lobular BC & 3.189 & $1.55 \mathrm{E}-27$ & 12.159 & Curtis [17] \\
\hline & Invasive ductal $\mathrm{BC}$ & 5.072 & $1.71 \mathrm{E}-4$ & 5.760 & Karnoub [19] \\
\hline & Invasive ductal BC & 4.877 & 0.029 & 2.489 & Turashvili [20] \\
\hline & Invasive lobular BC & 5.006 & 0.047 & 2.115 & Turashvili [20] \\
\hline & Invasive ductal BC & 4.915 & 0.017 & 2.349 & Ma [21] \\
\hline & Ductal BC in situ & 8.12 & 0.010 & 2.597 & $\mathrm{Ma}[21]$ \\
\hline & Ductal BC in situ epithelia & 6.157 & 0.012 & 6.157 & Мa [21] \\
\hline \multirow[t]{11}{*}{ CXCL11 } & Invasive ductal BC & 10.712 & $2.81 \mathrm{E}-5$ & 5.279 & Karnoub [19] \\
\hline & Ductal BC & 12.741 & $1.52 \mathrm{E}-9$ & 7.494 & Richardson[18] \\
\hline & Invasive $\mathrm{BC}$ & 8.811 & $1.69 \mathrm{E}-25$ & 13.055 & TCGA \\
\hline & Invasive ductal BC & 5.867 & $2.08 \mathrm{E}-31$ & 15.594 & TCGA \\
\hline & Invasive lobular BC & 5.268 & 8.07E-11 & 7.777 & TCGA \\
\hline & Medullary BC & 2.189 & 7.13E-6 & 5.134 & Curtis [17] \\
\hline & Invasive ductal $\mathrm{BC}$ & 7.089 & 0.009 & 3.222 & Radvanyi [22] \\
\hline & Invasive lobular BC & 3.724 & 0.038 & 2.066 & Radvanyi [22] \\
\hline & Invasive mixed BC & 4.123 & 0.029 & 2.422 & Radvanyi [22] \\
\hline & Ductal BC in situ stroma & 6.014 & 0.004 & 3.200 & Ma [21] \\
\hline & Invasive ductal BC stroma & 3.094 & 0.011 & 2.777 & Мa [21] \\
\hline \multirow[t]{2}{*}{ CXCL16 } & Invasive lobular BC & 2.369 & 0.016 & 2.413 & Radvanyi [22] \\
\hline & Invasive ductal BC & 2.225 & 0.014 & 2.571 & Radvanyi [22] \\
\hline CXCL17 & $\begin{array}{l}\text { Invasive BC } \\
\text { B }\end{array}$ & 2.257 & $1.67 \mathrm{E}-12$ & 10.984 & Finak [23] \\
\hline
\end{tabular}

Table 2. Prognostic association of CXC-chemokines expression in breast cancer based on bc-GenExMiner v4.0. (Event: metastatic recurrence). Abbreviations: MR, metastatic recurrence

\begin{tabular}{lcccc}
\hline Chemokine & Event & p-value & HR & $95 \%$ CI \\
\hline CXCL1 & MR & 0.6277 & 0.98 & $0.93-1.05$ \\
CXCL2 & MR & 0.0020 & 0.90 & $0.84-0.96$ \\
CXCL3 & MR & 0.2543 & 0.96 & $0.91-1.03$ \\
CXCL4 & MR & 0.9770 & 1.00 & $0.94-1.06$ \\
CXCL5 & MR & 0.1935 & 0.95 & $0.88-1.03$ \\
CXCL6 & MR & 0.0565 & 0.94 & $0.89-1.00$ \\
CXCL7 & MR & 0.3720 & 0.97 & $0.91-1.04$ \\
CXCL8 & MR & $<0.0001$ & 1.20 & $1.13-1.28$ \\
CXCL9 & MR & 0.1288 & 0.95 & $0.90-1.01$ \\
CXCL10 & MR & 0.3621 & 1.03 & $0.97-1.09$ \\
CXCL11 & MR & 0.8691 & 1.01 & $0.94-1.07$ \\
CXCL12 & MR & $<0.0001$ & 0.81 & $0.76-0.86$ \\
CXCL13 & MR & $<0.0001$ & 0.83 & $0.78-0.89$ \\
CXCL14 & MR & $<0.0001$ & 0.87 & $0.82-0.92$ \\
CXCL16 & MR & 0.9349 & 1.00 & $0.90-1.10$ \\
CXCL17 & MR & 0.0512 & 1.09 & $1.00-1.20$ \\
\hline
\end{tabular}


A
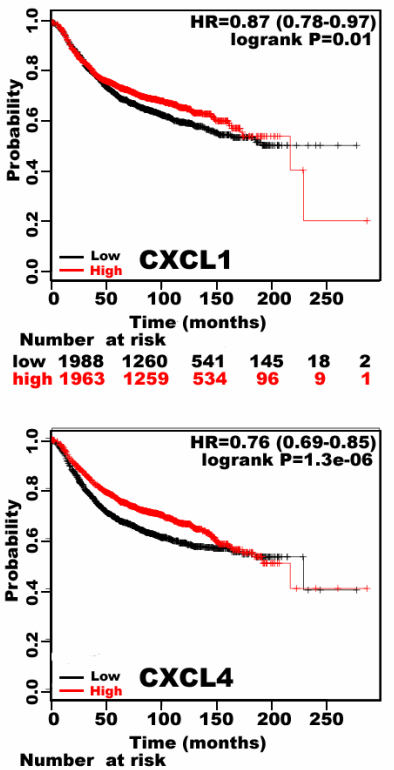
$\begin{array}{llllll}\text { low } 1980 & 1150 & 454 & 126 & 17 & 1 \\ \text { high } 1971 & 1369 & 621 & 115 & 10 & 2\end{array}$

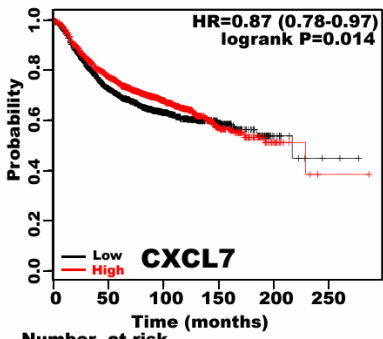

Nime (months)

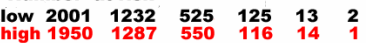

B

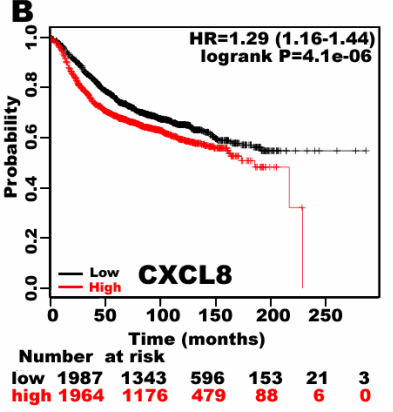

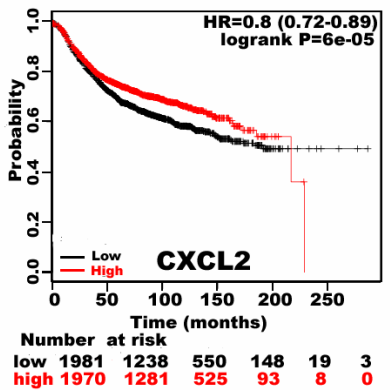
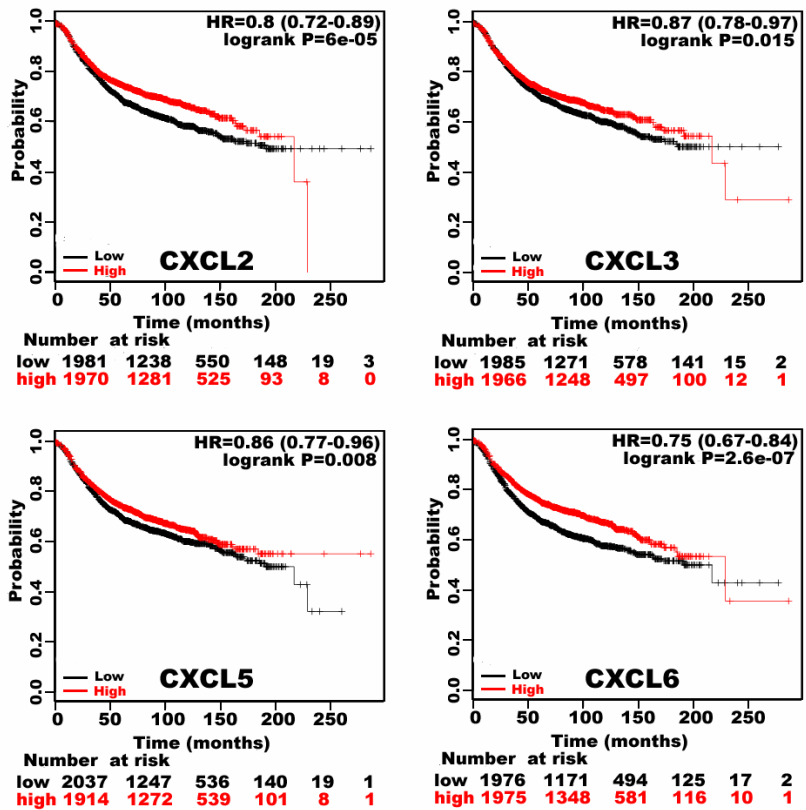

Number at risk

$\begin{array}{llllll}\text { low } 1976 & 1171 & 494 & 125 & 17 & 2 \\ \text { high } 1975 & 1348 & 581 & 116 & 10 & 1\end{array}$
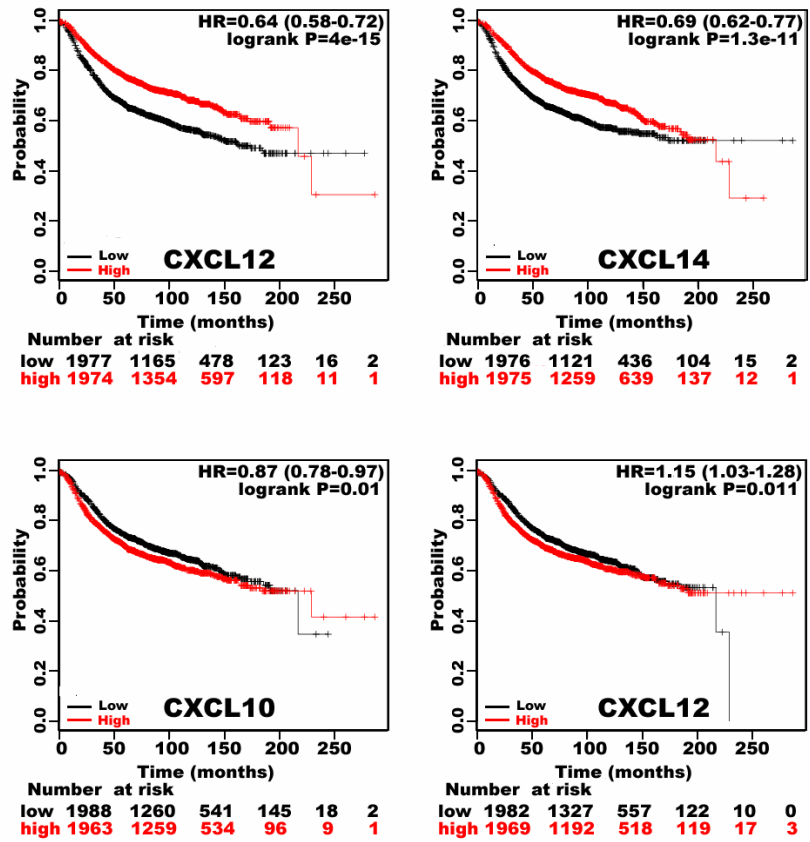

Fig. 2. Kaplan-Meier curve reveals the relapse-free survival differences based on mRNA level of CXC chemokines in BC patients. (A) BC patients with over expression of CXCL1/2/3/4/5/6/7/12/14 presented with better relapse-free survival (RFS). (B) BC patients with decreased expression of CXCL8/10/11 presented with better RFS.

the threshold of P-value $\leq 1 \mathrm{E}-4$, Fold Change $\geq 2$, and Gene Rank $\geq$ Top 10\%). This is true that IL-8 is not regulated in BC with this threshold. But IL-8 is overexpressed in BC with the threshold of P-value $\leq 0.05$, Fold Change $\geq 2$, and Gene Rank $\geq$ Top $10 \%$. When the chemokine expression of cancer is higher than that of adjacent non-tumor, we defined it as high expression and vice versa. The Kaplan-Meier curves for survival data indicated that increased CXCL1/2/3/4/5/6/7/12/14 mRNA levels and reduced CXCL8/10/11 mRNA levels are 


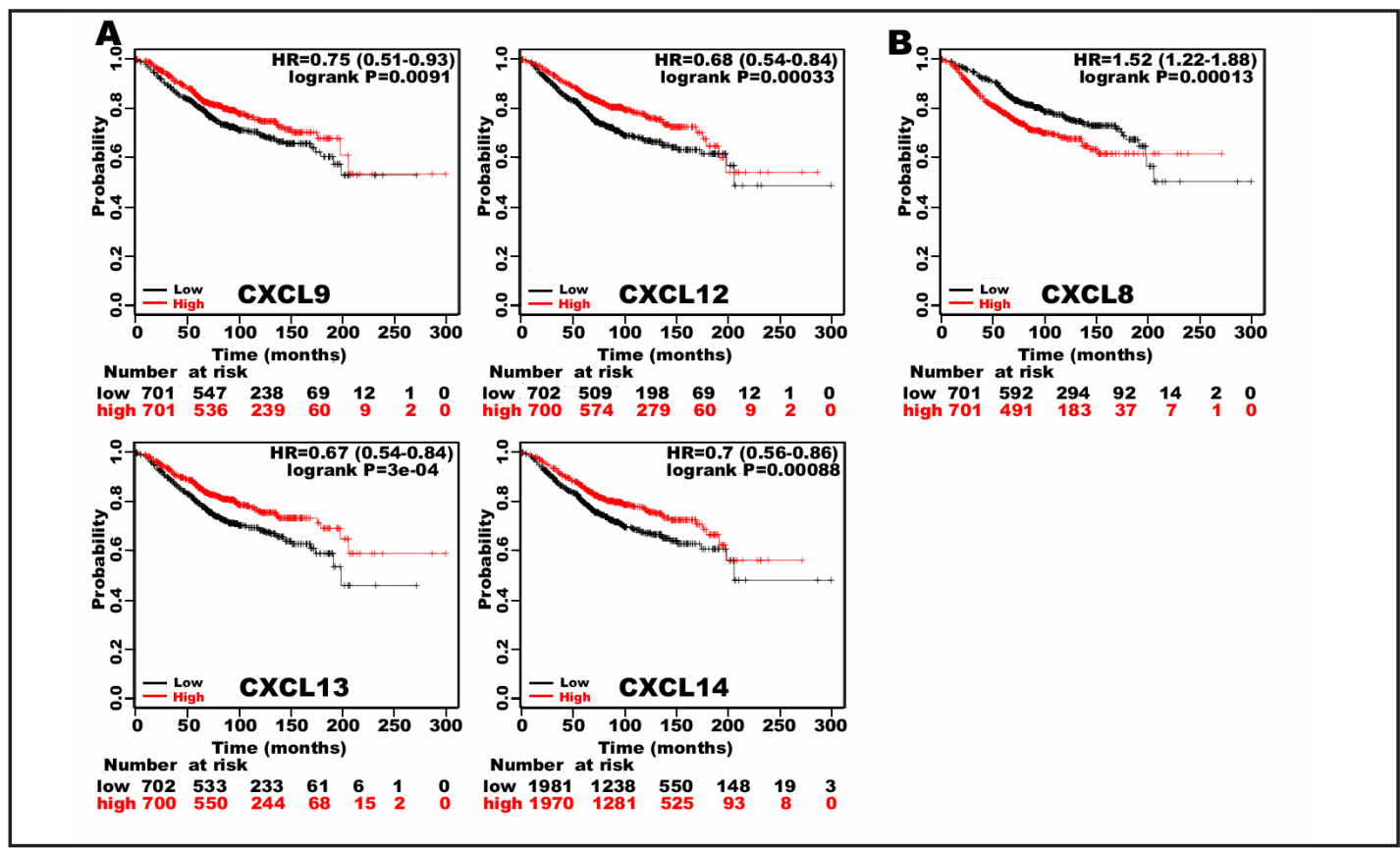

Fig. 3. Kaplan-Meier plotter reveals the overall survival differences based on mRNA level of CXC chemokines in BC patients. (A) BC patients with overexpression of CXCL9/12/13/14 presented with better overall survival (OS). (B) BC patients with decreased expression of CXCL8 presented with better OS.

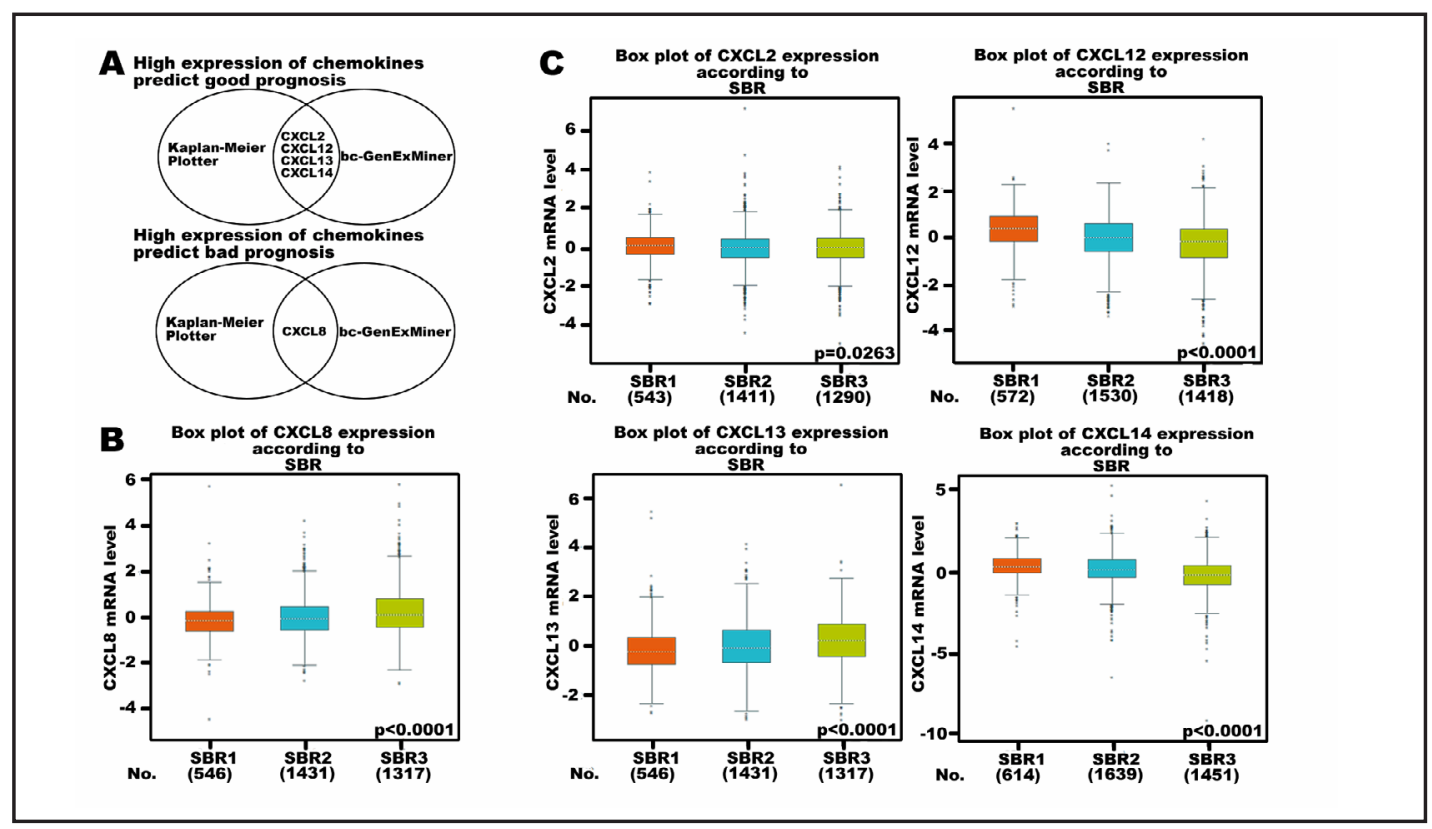

Fig. 4. The relationship between mRNA expression of CXC chemokines and Scarff Bloom \& Richardson grade status. (A) Diagrams shows the number of CXC chemokines identified as potential good/bad prognostic targets of BC between Kaplan-Meier Plotter and bcGenExMiner v4.0. (B) Global significant differences between groups was assessed by Welch's test to determine $p$ value $(p<0.05)$.

strongly correlated with RFS ( $<<0.05$ ) in all BC types (Fig. 2). Furthermore, BC patients with higher transcriptional levels of CXCL9/12/13/14 or lower mRNA levels of CXCL8 demonstrated better overall survival (OS) (Fig. 3). To further investigate chemokine roles in 
Fig. 5. The relationship between mRNA expression of CXCL2/8/12/13/14 expression of ER or PR and clinic pathological parameters of breast carcinoma (A) The relationship between mRNA expression of CXCL2/8/12/13/14 and clinic pathological parameters of breast carcinoma. (B) The relationship between mRNA expression of CXCL2/8/12/13/14 and protein expression of ER or PR. and the protein

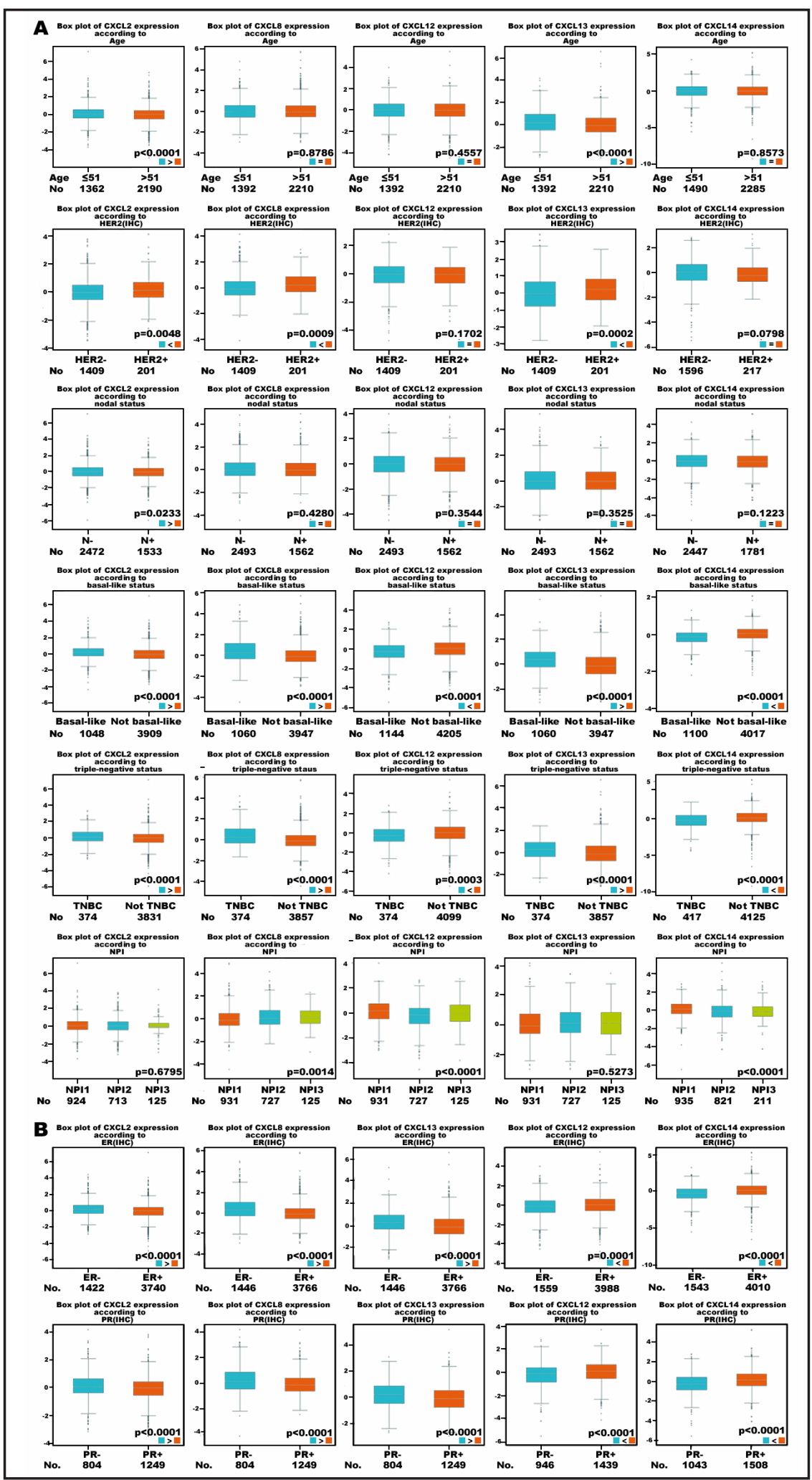

the prognosis of $\mathrm{BC}$, we also use bc-GenExMiner v4.0 to verify our findings. CXCL8 exerts the most significant negative effect on patient prognosis, and expression of CXCL2/12/13/14 was associated with better prognosis (Table 2). 
The relevance between aberrantly expressed CXC chemokines and clinical pathological parameters of $B C$ patients

Using the abovementioned databases, we next focused on whether CXCL2/12/13/14 and CXCL8 play pivotal roles in BC progression (Fig. 4A). Using bc-GenExMiner software, Welch's test was implemented to compare the aberrant expression of CXC chemokines between groups of patients based on different clinical pathological parameters. For age criterion (Fig. $5 \mathrm{~A}$ ), there was no significant difference between $\leq 51$ year and $>51$ year groups, except for CXCL2/13, which demonstrated reduced levels in the older group. BC patients with negative nodal status showed lower expression of CXCL2 than did positive nodal patients.

As shown in Fig. 5B, ER-positive or PR-positive patients tended to express low levels of CXCL2/8/13 and high levels of CXCL12/14 compared with ER-negative or PR-negative patients. ER-positive and PR-positive cancer cells depend on estrogen for their growth, so they can be treated with drugs to block estrogen effects (e.g., tamoxifen) and generally have a better prognosis [24]. Therefore, these results indicate that low expression of CXCL2/8/13 and high expression of CXCL12/14 may predict a better prognosis._In addition, CXCL2/8/13 expression was positively associated with HER2 status. Triple negative breast cancer (TNBC) is the most lethal type of $\mathrm{BC}$, with a molecular signature including ER (-), PR (-) and HER2 $(-)$. We found that CXCL2/8/13 mRNA expression was significantly increased in TNBC patients, while CXCL12/14 mRNA expression were significantly reduced in TNBC patients; the same pattern of change was observed in basal-like BC (Fig. 5).

The Scarff, Bloom \& Richardson grade (SBR) is an accepted prognostic factor that evaluates tubule formation, nuclear characteristics of pleiomorphism, and mitotic index. Patients with poorly differentiated tumors (grades II and III) have a decreased survival rate compared with those who have well-differentiated tumors (grade I). Based on SBR criterion (Fig. 4B, C), patients with high grade tumors (grades II and III) tended to express high levels of CXCL8 and low levels of CXCL2/12/14, consistent with our previous data. Apart from molecular subtypes, the Nottingham Prognostic Index (NPI) is also a useful prognostic model for BC patients. We found that lower expression of CXCL8 and higher expression of CXCL12/14 were correlated with the NPI. Combined with this information, multiple bioinformatics analyses identify CXCL8/12/14 as potential suitable therapeutic targets for BC patients. To visualize potential genes co-expressed with CXCL2/8/12/13, we constructed the gene network shown in Fig. 6. The network is meant to identify potential interactions between CXCL2/8/12/13 and other key proteins. As shown in Fig. 5, we found that CXCL2 was associated with other chemokines, including CXC L $1 / 3$ / 4 / 6/11/12 and CCL28. CXCL8 was associated with IL15 and IL12. Of note, PIK3CA was related to both CXCL8 and CXCL12 expression. Erb-b2 receptor tyrosine kinase 2 (ERBB2), a key modulator of breast cancer

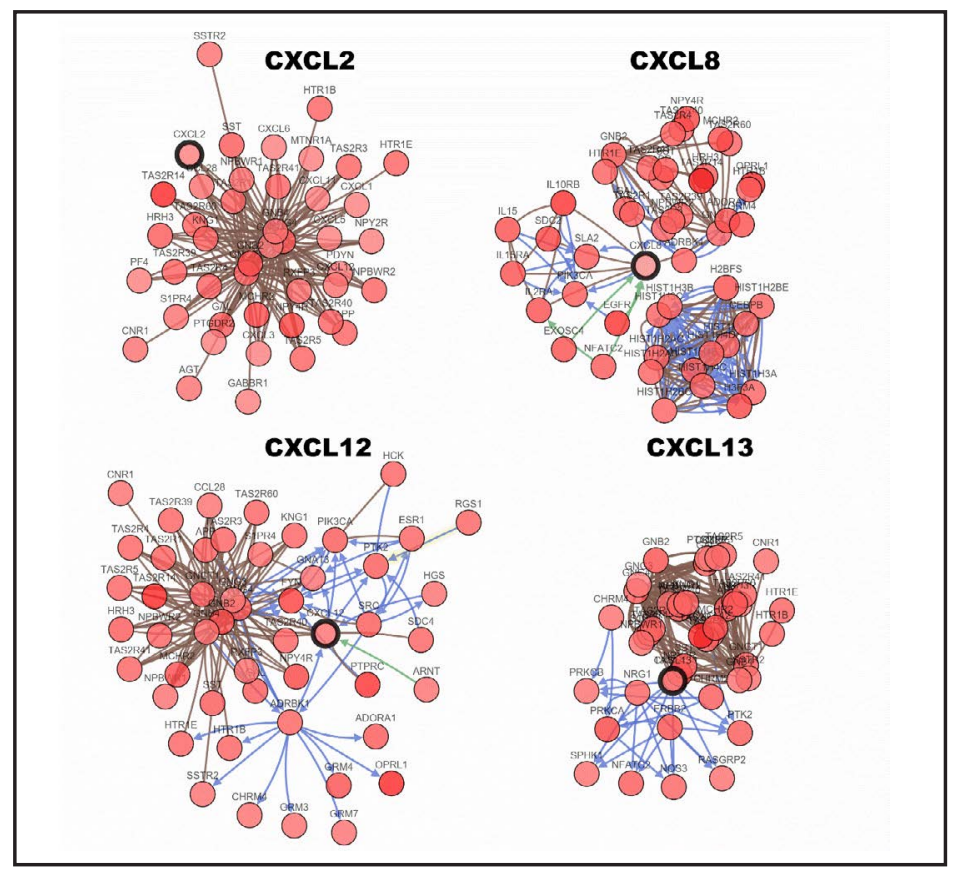

Fig. 6. Prospective gene networks of four differential CXC chemokines. To explore the regulation network of CXCL2/8/12/13, we show coexpressed genes of those key genes screened out by ONCOMINE. 
progression, was involved with CXCL13. This network analysis provides a series of gene candidates to help elucidate the molecular mechanisms of CXC chemokine involvement in BC.

\section{Discussion}

CXC chemokines have primarily been identified as chemo-attractive cytokines that are mainly involved in the maturation and differentiation of leukocytes. It has become clear that chemokine expression in BC plays a role in multiple aspects of neoplasia, including proliferation, survival, apoptosis, chemoattraction, angiogenesis, invasion and metastasis. Furthermore, cell-tocell communication between $\mathrm{BC}$ cells and interstitial cells impacts chemokine expression patterns in a variety of cell types, favoring a specific microenvironment that promotes tumor invasion and metastasis. There are conflicting reports on the roles of CXC chemokines within cancer. Recently, Nagarsheth et al. published a systematic review of chemokines in the cancer microenvironment and their relevance to cancer immunotherapy [4], indicating the crucial roles of CXC chemokine signaling pathways in multiple cancers and the efficacy

Table 5. Prognostic association of CXC-chemokines expression in breast cancer based on Kaplan-Meier Plotter. (Event: relapse-free survival)

\begin{tabular}{lccccc}
\hline Variable & Cutoff value expression & Expression & P value & HR & No. Patients \\
\hline CXCL1 & 109 & $1-26780$ & 0.0104 & $0.87(0.78-0.97)$ & 3951 \\
CXCL2 & 173 & $2-12317$ & 0.0001 & $0.8(0.72-0.89)$ & 3951 \\
CXCL3 & 42 & $1-4710$ & 0.0154 & $0.87(0.78-0.97)$ & 3951 \\
CXCL4 & 56 & $2-1980$ & $1.30 \mathrm{E}-06$ & $0.76(0.69-0.85)$ & 3951 \\
CXCL5 & 24.67 & $1-5166$ & 0.0015 & $0.84(0.75-0.93)$ & 3951 \\
CXCL6 & 48 & $1-4136$ & $2.60 \mathrm{E}-07$ & $0.75(0.67-0.84)$ & 3951 \\
CXCL7 & 22 & $1-7447$ & 0.0145 & $0.87(0.78-0.97)$ & 3951 \\
CXCL8 & 112.5 & $4-28546$ & $5.70 \mathrm{E}-07$ & $1.32(1.18-1.47)$ & 3951 \\
CXCL9 & 1120 & $6-28997$ & 0.96 & $1(0.9-1.12)$ & 3951 \\
CXCL10 & 1429 & $16-31023$ & $3.20 \mathrm{E}-03$ & $1.18(1.06-1.31)$ & 3951 \\
CXCL11 & 188 & $1-12392$ & 0.0027 & $1.18(1.06-1.32)$ & 3951 \\
CXCL12 & 1464 & $60-9818$ & $2.00 \mathrm{E}-11$ & $0.69(0.62-0.77)$ & 3951 \\
CXCL13 & 380 & $1-37026$ & 0.11 & $0.91(0.82-1.02)$ & 3951 \\
CXCL14 & 2529.5 & $2-66318$ & $2.10 \mathrm{E}-07$ & $0.66(0.57-0.77)$ & 1764 \\
CXCL16 & 597 & $63-5822$ & 0.0052 & $0.8(0.69-0.94)$ & 1764 \\
\hline
\end{tabular}
of immunotherapies. However, the role of distinct CXC chemokines in the progression and metastasis of $\mathrm{BC}$ remain to be elucidated. To our knowledge, this is the first study to identify specific CXC chemokines with prognostic value and biological function in the tumor microenvironment using integrative bioinformatics (Table 4 and 5).

\section{Literature Review of Dysregulated CXC chemokines in breast cancer}

A mini review of these CXC chemokines, their location, characteristics and known downstream targets is discussed below to suggest possible functional roles in breast tumorigenesis. 


\section{Cellular Physiology Cell Physiol Biochem 2018;45:1731-1746 \\ \begin{tabular}{l|l} 
and Biochemistry Published online: March 01, 2018 & $\begin{array}{l}\text { DOI: } 2018 \text { The Author(s). Published by S. Karger AG, Basel } \\
\text { www.karger.com/cpb }\end{array}$
\end{tabular} \\ Chen et al.: Therapeutic Targets Among CXCLs in TME}

\section{CXCL1/2/3/4/5/6/7/8/9/16/17 as oncogenes}

CXCL1, the first member of the CXC chemokine family, is considered an oncogene in BC. Cancer cells that overexpress CXCL1 attract CD11b+Gr1+ myeloid cells into the tumor stroma, stimulating secretion of S100A8/9, which enhances cancer cell survival and chemoresistance [25]. A pro-inflammatory interleukin, (IL)-17, significantly increases secretion of CXCL1 from breast carcinoma cells, suppressing function of myeloid-derived suppressor cells (MDSCs). MiR-200 was found to have both direct and indirect mechanisms of targeting CXCL1 to inhibit cancer angiogenesis [26]. In an experimental animal model, after co-injection of CXCL1 with human adipose-derived mesenchymal stem cells (hADSCs), hADSCs promoted residual BC proliferation and metastasis via the PI3K/AKT/SOX2 axis [27]. CXCL2 shares $90 \%$ amino acid homology with CXCL1. As a pro-inflammatory and pro-oncogenic factor, BC patients with high CXCL2 mRNA levels have a prognostic disadvantage. Kronski et al. has shown that miR-181b modulates the expression of CXCL1 and CXCL2, inhibiting breast cancer growth and invasion [28]. Constitutive CXCL3 activation has been reported in some human cancers with a poor prognosis as a potential therapeutic target [29]. Bone-marrow-derived mesenchymal stem cells (MSCs) may facilitate breast cancer progression by releasing CXCL3 with transforming growth factor- $\alpha$ (TGF $\alpha$ ) [30]. As few studies have focused on CXCL3, the underlining function of CXCL3 still needs additional research. CXCL4, known as platelet factor 4 (PF4), is released from activated platelets and binds with high affinity to heparin. In a mouse model, CXCL4 was shown to reduce breast cancer growth and proliferation of endothelial cells in vivo [31]. Of note, CXCL4 is produced by Ly6G+CD11b+ myeloid cells in the pre-metastatic stage, but production is lowered in the metastatic stage [32]. Controversially, Pucci et al. reported that CXCL4 induces platelet accumulation to promote lung adenocarcinoma in a demonstration of tumor-host communication [33]. There is little information on CXCL5 in BC. In the bone metastasis microenvironment, breast tumor associated osteoblasts (TAOs) secrete CXCL5 to mediate cancer development via the ERK/MSK1/Elk-1/Snail signaling pathway [34]. As mentioned above, (IL)-17 significantly increases secretion of CXCL1 and CXCL5 from breast carcinoma cells, suppressing the function of MDSCs [35]. As its former name granulocyte protein 2 (GCP-2) indicates, CXCL6 is a chemoattractant for neutrophils. Neutrophils within tumor stroma facilitate cancer invasion and metastasis. Due to lack of original research articles concerning the role of CXCL6 in BC, we speculate that CXCL6 may serve as a protooncogene in the tumor microenvironment [36]. CXCL7 is an isoform of pro-platelet basic protein (PPBP), which is released from activated platelets. In cell-to-cell communication between breast cancer stem cells (CSCs) and MSCs, CSCs produce IL6 to attract MSCs, which produce CXCL7 in response to IL6. In turn, CXCL7 induces the secretion of many cytokines from mesenchymal cells, including IL6, IL8, CXCL6 and CXCL5 [37].

CXCL8, previously called IL8, is a cytokine involved in cell-cell communication between cancer cells and neutrophils in the breast carcinoma microenvironment. Some transcription factors orchestrate key functions for increasing levels of CXCL8. The nuclear factor of activated T cells (NFAT) stimulates expression of CXCL8 by binding to its promoter and soliciting neutrophils in vitro and in vivo [38]. Tumor necrosis factor $\alpha$ (TNF $\alpha$ )-activated mesenchymal stromal cells accelerate breast tumor progression via neutrophil aggregation [39]. Considering hormone receptor criteria, CXCL8 deficiency inhibits hormone-resistant cell growth and invasion, in part attenuating the effect of Forkhead box protein A1 (FOXA1) function in ER+ breast cancer [40].

CXCL9/10/11/12/13/14 as tumor suppressors

CXCL9, known as monokine induced by gamma interferon (MIG), is a T-cell chemoattractant that is usually induced by IFN- $\gamma$. We found that high transcription levels of CXCL9 conferred an overall survival advantage in all BC patients, consistent with previous findings. Some researchers have already discovered that IFN- $\gamma$ exhibits a powerful influence on the secretion and expression of CXCL9 and CXCL10 $[41,42]$. The GeparSixto trial revealed that as an immune-activating factor, CXCL9 shows a positive correlation with PD-1 [43]. Brackett et al., found that the toll-like receptor-5 agonist entolimod quickly activates an 


\section{Cellular Physiology Cell Physiol Biochem 2018;45:1731-1746

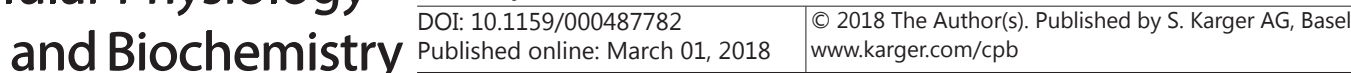 \\ Chen et al.: Therapeutic Targets Among CXCLs in TME}

innate antitumor response predominantly by attracting CXCR3+ NK cells using CXCL9 and CXCL10 [44]. Our study confirms that high transcription levels of CXCL9 confer an overall survival advantage in all $\mathrm{BC}$ patients and is a promising prognostic factor.

Intratumoral hypoxia triggers metastasis by activation and release of hypoxia-inducible factors (HIFs). Under hypoxic conditions, breast cancer cells increase HIF activity via MSC and cancer cell communication. Additionally, co-existence of two kinds of cells induce expression of the chemokine CXCL10 in MSCs to support metastasis to lymph nodes and lungs $[45,46]$. However, in recent studies, the idea of CXCL10 as a potent chemoattractant has received more attention. For example, type I IFNs trigger autocrine and paracrine circuits that accelerate the release of CXCL10 [47]. Mammary epithelial cells (MECs) create elevated expression of CXCL10 via type I IFNs as well [48]. Notably, combinatorial therapy with celecoxib and PD-1 mAb increases expression of CXCL9 and CXCL10 [49].

It has been demonstrated that CXCL11 has similar chemotactic functions as CXCL9 and is located near the CXCL9 gene on human chromosome 4. Unfortunately, not much research has focused on CXCL11 in BC. The stimulation of IFN genes (STING) triggers macrophage production of TNF $\alpha$ and high expression levels of the T cell-recruiting chemokines CXCL10 and CXCL11 [50].

Many different interstitial cell subsets are recruited into the tumor microenvironment via cell-to-cell communication between CXCL12 and its receptor CXCR4. However, CXCL12 and CXCR4 have disparate functions on breast tumorigenesis and outcomes depending on the specific immune cell type and conditions present [51]. Yu et al. demonstrated that transforming growth factor $\beta$ (TGF $\beta$ ) impairs MSCs ability to secrete CXCL12 and therefore promotes breast cancer metastasis [52], consistent with our findings. Recently, Xia et al. found that B cells directly kill BC cells using CXCR4/CXCL12 pathways, indicating that CXCL12 functions as a tumor suppressor [53]. Bioinformatics analysis also suggested that CXCL12 is an independent prognostic indicator. Contradictorily, CXCL12 is robustly increased in perivascular sites after chemotherapy, where it also carries out chemotaxis for tumorassociated macrophages [54].

CXCL13, known as B lymphocyte chemoattractant (BCL), was frequently found in the interaction between cancer cells and B cells [55]. ROR $\gamma \mathrm{t}+$ group 3 innate lymphoid also stimulated the expression of CXCL13 by stromal cells in the microenvironment and largely contributed to lymph node metastases [56]. Additionally, p53 deficiency was shown to activate CXCR5 expression in response to CXCL13 [57]. Nonetheless, Stoll et al. stated that expression of CXCL13 cardinally reflects the levels of effector T cells within the tumor bed, suggesting that CXCL13 might have a suppressive role in tumor progression [58].

Previously, CXCL14's role as a negative modulator of cancer growth and metastasis seemed well established [59]; however, a recent investigation revealed that CXCL14 might actually assist in tumor development and progression. Epithelial CXCL14 levels are markedly correlated with $\mathrm{ER}^{+}$tumors and lower proliferation status. Interestingly, total (epithelial and stromal) CXCL14 level is dramatically associated with decreased RFS [60]. Cross-talk between cancer cells and cancer-associated fibroblasts (CAFs) is also relevant to cancer research. CXCL14 is a potent executor of CAFs' pro-tumorigenic functions. Of note, nitric oxide synthase (NOS1) has increased expression in CAF and, with CXCL14, stimulates CAFs. NOS1 can speed up tumor growth with the assistance of CXCL14-expressing CAFs [61]. Furthermore, lower miR-29b expression in CAFs can accelerate metastasis by activating the p38-STAT1 pathway in breast cancer cells and up-regulating CXCL14 and CCL11 in CAFs. Additionally, STAT1 increases expression of CXCL14 and CCL11 at the transcription level [62]. Kaplan-Meier curves revealed that high CXCL14 mRNA levels were correlated with favorable relapse-free survival (RFS) in all types of BC patients, and high transcription levels of CXCL14 conferred an overall survival (OS) advantage in all BC patients. These results suggest that CXCL14 is a potential target for precision therapy in $\mathrm{BC}$ patients.

BC cells secrete CXCL16 that binds to CXCR6 on MSCs. In turn, MSCs secrete CXCL10 that binds to CXCR3 on cancer cells. This feedback loop drives accumulation of tumor-associated macrophages (TAMs) and MDSCs [46]. CXCR6 was found not only in stromal cells but was also 


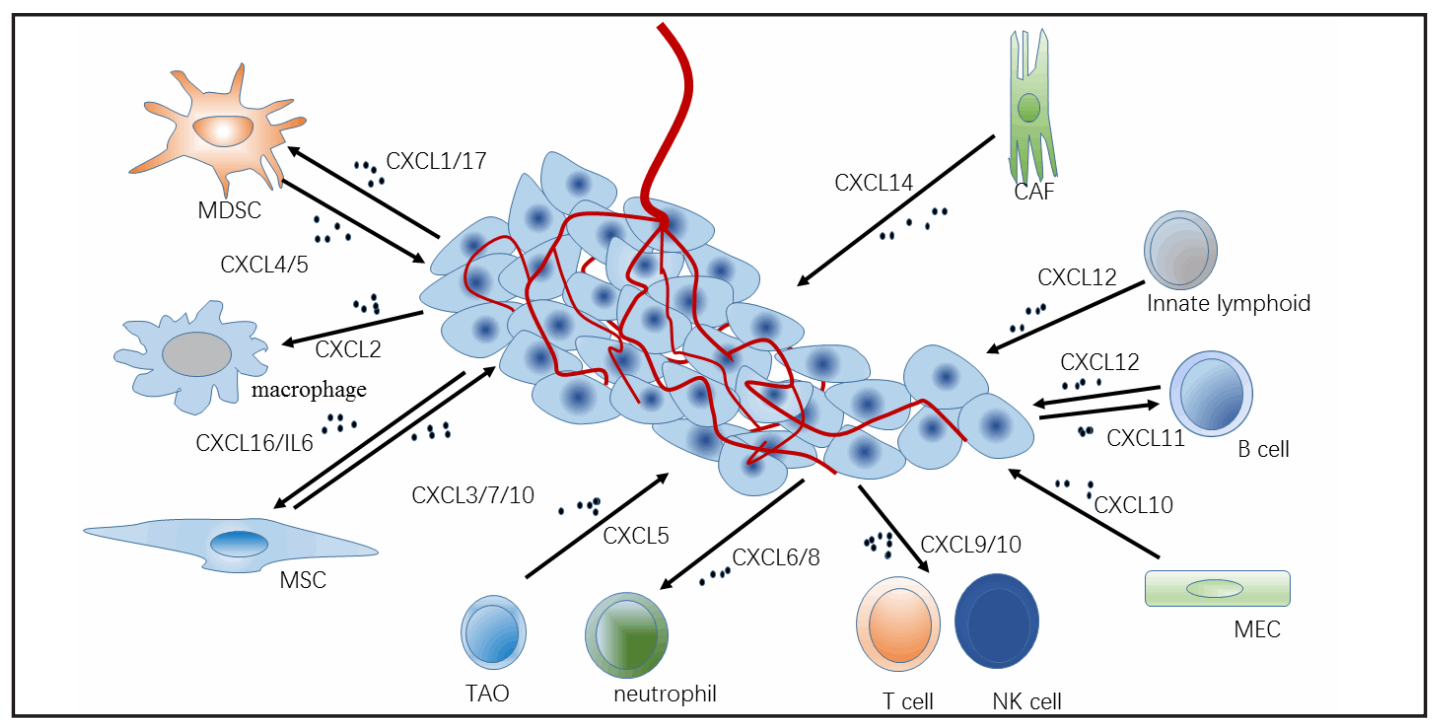

Fig. 7. Cross-talk between BC cells and immune cells mediated by CXC chemokines in the tumor microenvironment. The immune system is determined by the recruitment of various immune cells through secretion of CXC chemokines by tumor cells and other infiltrating immune cells in the tumor microenvironment. DMSC, myeloid-derived suppressor cell; MSC, mesenchymal stem cell; TAO, tumor associated osteoblast; NK cell; nature killer cell; MEC, mammary epithelial cell; CAF, cancer associated fibroblast; IL-6, interleukin-6.

constitutively expressed in cancer cells. BC cells mediate production of autocrine CXCL16, promoting cancer progression via pERK1/2 signaling [63]. On the other hand, stromal cells like CAFs can secrete CXCL16, a chemoattractant for monocytes that contributes to the aggressive phenotype of TNBC [64].

CXCL17 is also called VEGF co-regulated chemokine 1 (VCC-1) and dendritic cell- and monocyte-attracting chemokine-like protein (DMC). Cancer cell-derived CXCL17 recruits MDSCs to tumor sites and facilitates tumorigenesis and angiogenesis [65].

\section{Comparison of mini review of CXC chemokines with our results}

Overall, we illustrated that cross-talk between breast cancer cells and immune cells is mediated by CXC chemokines in the tumor microenvironment (Fig. 7 and Table 3). Although CXC chemokines are reported to affect OS and RFS in BC patients, the dominant regulatory factors and underlying mechanism are still unclear. The exact mechanism of CXC chemokine involvement in $\mathrm{BC}$ patient prognosis requires more investigation.

The above mini-review indicates that CXCL1/2/3/4/5/6/7 may function as protooncogenes in the tumor microenvironment, which contradicts our findings. The CXC chemokine expression profiles in the dataset are primarily from RNA sequences. These disparities may stem from differences between clinical samples and experimental conditions used in each study. Of note, in this study, we report that CXCL8 mRNA level is significantly overexpressed in breast cancer and increased in higher SBR grades, which predict rapidgrowing, metastatic tumors. This result is consistent with previous reports. Furthermore, high levels of CXCL8 indicated shorter OS in all BC patients, representing a potential therapeutic target.

In the current study, we systemically analyzed transcriptional expression and prognostic values for all CXC chemokines in $\mathrm{BC}$, supplying a more profound understanding of the complicated dysregulation in the molecular biology of $\mathrm{BC}$. Integrative bioinformatics analysis suggests that CXCL8/12/14, compared to other CXC chemokines, are potential suitable targets for precision treatment in BC patients. However, other multiple clinical trials are required to validate the diagnostic potentials of these CXC chemokines. Additionally, more in-depth experiments, such as single cell sequencing, are necessary to explore the underlying mechanism of cross-talk between cancer cells and stromal cells in BC. 


\section{Cellular Physiology Cell Physiol Biochem 2018;45:1731-1746 \begin{tabular}{l|l} 
and Biochemistry Published online: March 01, 2018 & $\begin{array}{l}\text { (c) } 2018 \text { The Author(s). Published by S. Karger AG, Basel } \\
\text { www.karger.com/cpb }\end{array}$
\end{tabular} \\ Chen et al.: Therapeutic Targets Among CXCLs in TME}

\section{Abbreviations}

BC (breast cancer); RFS (relapse-free survival); OS (overall survival); ER (estrogen receptor); PR (progesterone receptor); HER2 (epidermal growth factor receptor 2); NK (cells nature killer cells); TCGA (The Cancer Genome Atlas); TNBC (triple negative breast cancer); SBR (Scarff, Bloom \& Richardson grade); NPI (Nottingham Prognostic Index); ERBB2 (Erb-b2 receptor tyrosine kinase 2); MDSCs (myeloid-derived suppressor cells); hADSCs (human adipose-derived mesenchymal stem cells); TGF $\alpha$ (transforming growth factor- $\alpha$ ); TAOs (tumor associated osteoblasts); GCP-2 (granulocyte protein 2); PPBP (pro-platelet basic protein); NFAT (nuclear factor of activated T cells); TNF $\alpha$ (tumor necrosis factor $\alpha$ ); FOXA1 (Forkhead box protein A1); HIFs (hypoxia-inducible factors); MECs (mammary epithelial cells); CAFs (cancer-associated fibroblasts); VCC-1 (VEGF co-regulated chemokine 1)

\section{Acknowledgements}

This research is supported by National Natural Science Foundation of China (81502003) and Shanghai Science and Technology Commission (17411951400).

\section{Disclosure Statement}

The authors disclose no competing interests in this research.

\section{References}

1 Siegel RL, Miller KD, Jemal A: Cancer statistics, 2016 CA Cancer J Clin 2016;66:7-30.

$\checkmark 2$ Miller KD, Siegel RL, Lin CC, Mariotto AB, Kramer JL, Rowland JH, Stein KD, Alteri R, Jemal A: Cancer treatment and survivorship statistics, 2016 CA Cancer J Clin 2016;66:271-289.

3 Li X, Sun S, Li N, Gao J, Yu J, Zhao J, Li M, Zhao Z: High Expression of CCR7 Predicts Lymph Node Metastasis and Good Prognosis in Triple Negative Breast Cancer. Cell Physiol Biochem 2017;43:531-539.

4 Nagarsheth N, Wicha MS, Zou W: Chemokines in the cancer microenvironment and their relevance in cancer immunotherapy. Nat Rev Immunol 2017

5 Verbeke H, Struyf S, Laureys G, Van Damme J: The expression and role of CXC chemokines in colorectal cancer. Cytokine Growth Factor Rev 2011;22:345-358.

6 Lohmann N, Schirmer L, Atallah P, Wandel E, Ferrer RA, Werner C, Simon JC, Franz S, Freudenberg U: Glycosaminoglycan-based hydrogels capture inflammatory chemokines and rescue defective wound healing in mice. Sci Transl Med 2017;9

7 Lim K, Hyun YM, Lambert-Emo K, Capece T, Bae S, Miller R, Topham DJ, Kim M: Neutrophil trails guide influenza-specific CD8(+) T cells in the airways. Science 2015;349:aaa4352.

8 Perrucci GL, Straino S, Corliano M, Scopece A, Napolitano M, Berk BC, Lombardi F, Pompilio G, Capogrossi MC, Nigro P: Cyclophilin A modulates bone marrow-derived CD117(+) cells and enhances ischemiainduced angiogenesis via the SDF-1/CXCR4 axis. Int J Cardiol 2016;212:324-335.

-9 Serti E, Chepa-Lotrea X, Kim YJ, Keane M, Fryzek N, Liang TJ, Ghany M, Rehermann B: Successful Interferon-Free Therapy of Chronic Hepatitis C Virus Infection Normalizes Natural Killer Cell Function. Gastroenterology 2015;149:190-200 e192.

10 Rhodes DR, Yu J, Shanker K, Deshpande N, Varambally R, Ghosh D, Barrette T, Pandey A, Chinnaiyan AM: ONCOMINE: a cancer microarray database and integrated data-mining platform. Neoplasia 2004;6:1-6.

-11 Jezequel P, Campone M, Gouraud W, Guerin-Charbonnel C, Leux C, Ricolleau G, Campion L: bc-GenExMiner: an easy-to-use online platform for gene prognostic analyses in breast cancer. Breast Cancer Res Treat 2012;131:765-775.

12 Jezequel P, Frenel JS, Campion L, Guerin-Charbonnel C, Gouraud W, Ricolleau G, Campone M: bcGenExMiner 3.0: new mining module computes breast cancer gene expression correlation analyses. Database (Oxford) 2013;2013:bas060.

13 Gyorffy B, Lanczky A, Eklund AC, Denkert C, Budczies J, Li Q Szallasi Z: An online survival analysis tool to rapidly assess the effect of 22, 277 genes on breast cancer prognosis using microarray data of 1, 809 patients. Breast Cancer Res Treat 2010;123:725-731. 


\section{Cellular Physiology Cell Physiol Biochem 2018;45:1731-1746 \begin{tabular}{l|l} 
and Biochemistry Published online: March 01, 2018 & $\begin{array}{l}\text { (c) } 2018 \text { The Author(s). Published by S. Karger AG, Basel } \\
\text { www.karger.com/cpb }\end{array}$
\end{tabular}}

Chen et al.: Therapeutic Targets Among CXCLs in TME

14 Cancer Genome Atlas N: Comprehensive molecular portraits of human breast tumours. Nature 2012;490:61-70.

15 Gao J, Aksoy BA, Dogrusoz U, Dresdner G, Gross B, Sumer SO, Sun Y, Jacobsen A, Sinha R, Larsson E, Cerami E, Sander C, Schultz N: Integrative analysis of complex cancer genomics and clinical profiles using the cBioPortal. Sci Signal 2013;6:pl1.

-16 Cerami E, Gao J, Dogrusoz U, Gross BE, Sumer SO, Aksoy BA, Jacobsen A, Byrne CJ, Heuer ML, Larsson E, Antipin Y, Reva B, Goldberg AP, Sander C, Schultz N: The cBio cancer genomics portal: an open platform for exploring multidimensional cancer genomics data. Cancer Discov 2012;2:401-404.

17 Curtis C, Shah SP, Chin SF, Turashvili G, Rueda OM, Dunning MJ, Speed D, Lynch AG, Samarajiwa S, Yuan Y, Graf S, Ha G, Haffari G, Bashashati A, Russell R, McKinney S, Group M, Langerod A, Green A, Provenzano E, Wishart G, Pinder S, Watson P, Markowetz F, Murphy L, Ellis I, Purushotham A, Borresen-Dale AL, Brenton JD, Tavare S, Caldas C, Aparicio S: The genomic and transcriptomic architecture of 2, 000 breast tumours reveals novel subgroups. Nature 2012;486:346-352.

18 Richardson AL, Wang ZC, De Nicolo A, Lu X, Brown M, Miron A, Liao X, Iglehart JD, Livingston DM, Ganesan S: X chromosomal abnormalities in basal-like human breast cancer. Cancer Cell 2006;9:121-132.

19 Karnoub AE, Dash AB, Vo AP, Sullivan A, Brooks MW, Bell GW, Richardson AL, Polyak K, Tubo R, Weinberg RA: Mesenchymal stem cells within tumour stroma promote breast cancer metastasis. Nature 2007;449:557-563.

20 Turashvili G, Bouchal J, Baumforth K, Wei W, Dziechciarkova M, Ehrmann J, Klein J, Fridman E, Skarda J, Srovnal J, Hajduch M, Murray P, Kolar Z: Novel markers for differentiation of lobular and ductal invasive breast carcinomas by laser microdissection and microarray analysis. BMC Cancer 2007;7:55.

21 Ma XJ, Dahiya S, Richardson E, Erlander M, Sgroi DC: Gene expression profiling of the tumor microenvironment during breast cancer progression. Breast Cancer Res 2009;11:R7.

-22 Radvanyi L, Singh-Sandhu D, Gallichan S, Lovitt C, Pedyczak A, Mallo G, Gish K, Kwok K, Hanna W, Zubovits J, Armes J, Venter D, Hakimi J, Shortreed J, Donovan M, Parrington M, Dunn P, Oomen R, Tartaglia J, Berinstein NL: The gene associated with trichorhinophalangeal syndrome in humans is overexpressed in breast cancer. Proc Natl Acad Sci U S A 2005;102:11005-11010.

-23 Finak G, Bertos N, Pepin F, Sadekova S, Souleimanova M, Zhao H, Chen H, Omeroglu G, Meterissian S, Omeroglu A, Hallett M, Park M: Stromal gene expression predicts clinical outcome in breast cancer. Nat Med 2008;14:518-527.

24 Glück S: Extending the Clinical Benefit of Endocrine Therapy for Women With Hormone Receptor-Positive Metastatic Breast Cancer: Differentiating Mechanisms of Action. Clinical Breast Cancer 2014;14:75-84.

25 Acharyya S, Oskarsson T, Vanharanta S, Malladi S, Kim J, Morris PG, Manova-Todorova K, Leversha M, Hogg N, Seshan VE, Norton L, Brogi E, Massague J: A CXCL1 paracrine network links cancer chemoresistance and metastasis. Cell 2012;150:165-178.

26 Pecot CV, Rupaimoole R, Yang D, Akbani R, Ivan C, Lu C, Wu S, Han HD, Shah MY, Rodriguez-Aguayo C, Bottsford-Miller J, Liu Y, Kim SB, Unruh A, Gonzalez-Villasana V, Huang L, Zand B, Moreno-Smith M, Mangala LS, Taylor M, et al.: Tumour angiogenesis regulation by the miR-200 family. Nat Commun 2013;4:2427.

27 Jeong HC, Park SJ, Choi JJ, Go YH, Hong SK, Kwon OS, Shin JG, Kim RK, Lee MO, Lee SJ, Shin HD, Moon SH, Cha HJ: PRMT8 Controls the Pluripotency and Mesodermal Fate of Human Embryonic Stem Cells by Enhancing the PI3K/AKT/SOX2 Axis. Stem Cells 2017

28 Kronski E, Fiori ME, Barbieri O, Astigiano S, Mirisola V, Killian PH, Bruno A, Pagani A, Rovera F, Pfeffer U, Sommerhoff CP, Noonan DM, Nerlich AG, Fontana L, Bachmeier BE: miR181b is induced by the chemopreventive polyphenol curcumin and inhibits breast cancer metastasis via down-regulation of the inflammatory cytokines CXCL1 and -2 Mol Oncol 2014;8:581-595.

29 Zhang L, Zhang L, Li H, Ge C, Zhao F, Tian H, Chen T, Jiang G, Xie H, Cui Y, Yao M, Li J: CXCL3 contributes to CD133(+) CSCs maintenance and forms a positive feedback regulation loop with CD133 in HCC via Erk1/2 phosphorylation. Sci Rep 2016;6:27426.

30 De Luca A, Roma C, Gallo M, Fenizia F, Bergantino F, Frezzetti D, Costantini S, Normanno N: RNA-seq analysis reveals significant effects of EGFR signalling on the secretome of mesenchymal stem cells. Oncotarget 2014;5:10518-10528.

- 31 Van Raemdonck K, Berghmans N, Vanheule V, Bugatti A, Proost P, Opdenakker G, Presta M, Van Damme J, Struyf S: Angiostatic, tumor inflammatory and anti-tumor effects of CXCL4(47-70) and CXCL4L1(47-70) in an EGF-dependent breast cancer model. Oncotarget 2014;5:10916-10933. 


\section{Cellular Physiology Cell Physiol Biochem 2018;45:1731-1746

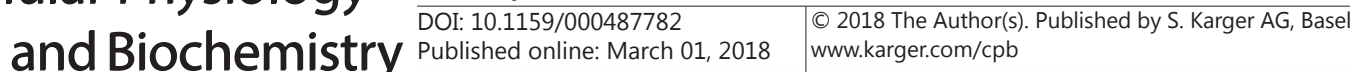

Chen et al.: Therapeutic Targets Among CXCLs in TME

-32 Jian. J, Pang. Y, Hollander. MC, Yan. HH, Lin. PC, Min. Y, Liang. X, Achyut. BR, Yang. L: Platelet factor 4 is produced by subsets of myeloid cells in premetastatic lung and inhibits tumor metastasis. oncotarget 2017;8:27725-27739.

-33 Pucci F, Rickelt S, Newton AP, Garris C, Nunes E, Evavold C, Pfirschke C, Engblom C, Mino-Kenudson M, Hynes RO, Weissleder R, Pittet MJ: PF4 Promotes Platelet Production and Lung Cancer Growth. Cell Rep 2016;17:1764-1772.

-34 Hsu YL, Hou MF, Kuo PL, Huang YF, Tsai EM: Breast tumor-associated osteoblast-derived CXCL5 increases cancer progression by ERK/MSK1/Elk-1/snail signaling pathway. Oncogene 2013;32:4436-4447.

35 Novitskiy SV, Pickup MW, Gorska AE, Owens P, Chytil A, Aakre M, Wu H, Shyr Y, Moses HL: TGF-beta receptor II loss promotes mammary carcinoma progression by Th17 dependent mechanisms. Cancer Discov 2011;1:430-441.

36 Lefort K, Ostano P, Mello-Grand M, Calpini V, Scatolini M, Farsetti A, Dotto GP, Chiorino G: Dual tumor suppressing and promoting function of Notch1 signaling in human prostate cancer. Oncotarget 2016;7:48011-48026.

37 Liu S, Ginestier C, Ou SJ, Clouthier SG, Patel SH, Monville F, Korkaya H, Heath A, Dutcher J, Kleer CG, Jung Y, Dontu G, Taichman R, Wicha MS: Breast cancer stem cells are regulated by mesenchymal stem cells through cytokine networks. Cancer Res 2011;71:614-624.

-38 Kaunisto A, Henry WS, Montaser-Kouhsari L, Jaminet SC, Oh EY, Zhao L, Luo HR, Beck AH, Toker A: NFAT1 promotes intratumoral neutrophil infiltration by regulating IL8 expression in breast cancer. Mol Oncol 2015;9:1140-1154.

-39 Yu PF, Huang Y, Han YY, Lin LY, Sun WH, Rabson AB, Wang Y, Shi YF: TNFalpha-activated mesenchymal stromal cells promote breast cancer metastasis by recruiting CXCR2+ neutrophils. Oncogene 2017;36:482490.

40 Fu X, Jeselsohn R, Pereira R, Hollingsworth EF, Creighton CJ, Li F, Shea M, Nardone A, De Angelis C, Heiser LM, Anur P, Wang N, Grasso CS, Spellman PT, Griffith OL, Tsimelzon A, Gutierrez C, Huang S, Edwards DP, et al.: FOXA1 overexpression mediates endocrine resistance by altering the ER transcriptome and IL-8 expression in ER-positive breast cancer. Proc Natl Acad Sci U S A 2016;113:E6600-E6609.

-41 Bronger H, Kraeft S, Schwarz-Boeger U, Cerny C, Stockel A, Avril S, Kiechle M, Schmitt M: Modulation of CXCR3 ligand secretion by prostaglandin E2 and cyclooxygenase inhibitors in human breast cancer. Breast Cancer Res 2012;14:R30.

42 Fluhr H, Seitz T, Zygmunt M: Heparins modulate the IFN-gamma-induced production of chemokines in human breast cancer cells. Breast Cancer Res Treat 2013;137:109-118.

43 Denkert C, von Minckwitz G, Brase JC, Sinn BV, Gade S, Kronenwett R, Pfitzner BM, Salat C, Loi S, Schmitt WD, Schem C, Fisch K, Darb-Esfahani S, Mehta K, Sotiriou C, Wienert S, Klare P, Andre F, Klauschen F, Blohmer JU, et al.: Tumor-infiltrating lymphocytes and response to neoadjuvant chemotherapy with or without carboplatin in human epidermal growth factor receptor 2-positive and triple-negative primary breast cancers. J Clin Oncol 2015;33:983-991.

44 Brackett CM, Kojouharov B, Veith J, Greene KF, Burdelya LG, Gollnick SO, Abrams SI, Gudkov AV: Toll-like receptor-5 agonist, entolimod, suppresses metastasis and induces immunity by stimulating an NKdendritic-CD8+ T-cell axis. Proc Natl Acad Sci U S A 2016;113:E874-883.

45 Chaturvedi P, Gilkes DM, Wong CC, Kshitiz, Luo W, Zhang H, Wei H, Takano N, Schito L, Levchenko A, Semenza GL: Hypoxia-inducible factor-dependent breast cancer-mesenchymal stem cell bidirectional signaling promotes metastasis. J Clin Invest 2013;123:189-205.

46 Chaturvedi P, Gilkes DM, Takano N, Semenza GL: Hypoxia-inducible factor-dependent signaling between triple-negative breast cancer cells and mesenchymal stem cells promotes macrophage recruitment. Proc Natl Acad Sci U S A 2014;111:E2120-2129.

-47 Sistigu A, Yamazaki T, Vacchelli E, Chaba K, Enot DP, Adam J, Vitale I, Goubar A, Baracco EE, Remedios C, Fend L, Hannani D, Aymeric L, Ma Y, Niso-Santano M, Kepp O, Schultze JL, Tuting T, Belardelli F, Bracci L et al.: Cancer cell-autonomous contribution of type I interferon signaling to the efficacy of chemotherapy. Nat Med 2014;20:1301-1309.

48 Burkart C, Arimoto K, Tang T, Cong X, Xiao N, Liu YC, Kotenko SV, Ellies LG, Zhang DE: Usp18 deficient mammary epithelial cells create an antitumour environment driven by hypersensitivity to IFN-lambda and elevated secretion of Cxcl10. EMBO Mol Med 2013;5:1035-1050. 


\section{Cellular Physiology Cell Physiol Biochem 2018;45:1731-1746

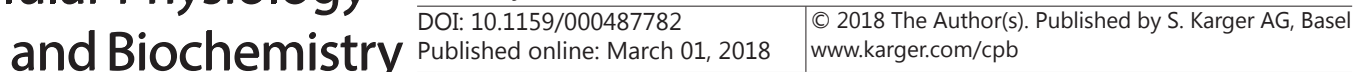

Chen et al.: Therapeutic Targets Among CXCLs in TME

49 Li Y, Fang M, Zhang J, Wang J, Song Y, Shi J, Li W, Wu G, Ren J, Wang Z, Zou W, Wang L: Hydrogel dual delivered celecoxib and anti-PD-1 synergistically improve antitumor immunity. Oncoimmunology 2016;5:e1074374.

50 Ohkuri T, Kosaka A, Ishibashi K, Kumai T, Hirata Y, Ohara K, Nagato T, Oikawa K, Aoki N, Harabuchi Y, Celis E, Kobayashi H: Intratumoral administration of cGAMP transiently accumulates potent macrophages for antitumor immunity at a mouse tumor site. Cancer Immunol Immunother 2017;66:705-716.

51 Azariadis K, Kiagiadaki F, Pelekanou V, Bempi V, Alexakis K, Kampa M, Tsapis A, Castanas E, Notas G: Androgen Triggers the Pro-Migratory CXCL12/CXCR4 Axis in AR-Positive Breast Cancer Cell Lines: Underlying Mechanism and Possible Implications for the Use of Aromatase Inhibitors in Breast Cancer. Cell Physiol Biochem 2017;44:66-84.

52 Yu PF, Huang Y, Xu CL, Lin LY, Han YY, Sun WH, Hu GH, Rabson AB, Wang Y, Shi YF: Downregulation of CXCL12 in mesenchymal stromal cells by TGFbeta promotes breast cancer metastasis. Oncogene 2017;36:840-849.

53 Xia Y, Tao H, Hu Y, Chen Q Chen X, Xia L, Zhou L, Wang Y, Bao Y, Huang S, Ren X, Lundy SK, Dai F, Li Q, Chang AE: IL-2 augments the therapeutic efficacy of adoptively transferred B cells which directly kill tumor cells via the CXCR4/CXCL12 and perforin pathways. Oncotarget 2016;7:60461-60474.

54 Hughes R, Qian BZ, Rowan C, Muthana M, Keklikoglou I, Olson OC, Tazzyman S, Danson S, Addison C, Clemons M, Gonzalez-Angulo AM, Joyce JA, De Palma M, Pollard JW, Lewis CE: Perivascular M2 Macrophages Stimulate Tumor Relapse after Chemotherapy. Cancer Res 2015;75:3479-3491.

55 Bodogai M, Lee Chang C, Wejksza K, Lai J, Merino M, Wersto RP, Gress RE, Chan AC, Hesdorffer C, Biragyn A: Anti-CD2 0 antibody promotes cancer escape via enrichment of tumor-evoked regulatory B cells expressing low levels of CD20 and CD137L. Cancer Res 2013;73:2127-2138.

56 Irshad S, Flores-Borja F, Lawler K, Monypenny J, Evans R, Male V, Gordon P, Cheung A, Gazinska P, Noor F, Wong F, Grigoriadis A, Fruhwirth GO, Barber PR, Woodman N, Patel D, Rodriguez-Justo M, Owen J et al.: RORgammat+ Innate Lymphoid Cells Promote Lymph Node Metastasis of Breast Cancers. Cancer Res 2017;77:1083-1096.

57 Mitkin NA, Hook CD, Schwartz AM, Biswas S, Kochetkov DV, Muratova AM, Afanasyeva MA, Kravchenko JE, Bhattacharyya A, Kuprash DV: p53-dependent expression of CXCR5 chemokine receptor in MCF-7 breast cancer cells. Sci Rep 2015;5:9330.

-58 Stoll G, Enot D, Mlecnik B, Galon J, Zitvogel L, Kroemer G: Immune-related gene signatures predict the outcome of neoadjuvant chemotherapy. Oncoimmunology 2014;3:e27884.

59 Gu XL, Ou ZL, Lin FJ, Yang XL, Luo JM, Shen ZZ, Shao ZM: Expression of CXCL14 and its anticancer role in breast cancer. Breast Cancer Res Treat 2012;135:725-735.

60 Sjoberg E, Augsten M, Bergh J, Jirstrom K, Ostman A: Expression of the chemokine CXCL14 in the tumour stroma is an independent marker of survival in breast cancer. Br J Cancer 2016;114:1117-1124.

-61 Augsten M, Sjoberg E, Frings O, Vorrink SU, Frijhoff J, Olsson E, Borg A, Ostman A: Cancer-associated fibroblasts expressing CXCL14 rely upon NOS1-derived nitric oxide signaling for their tumor-supporting properties. Cancer Res 2014;74:2999-3010.

-62 Liu Y, Zhang J, Sun X, Su Q You C: Down-regulation of miR-29b in carcinoma associated fibroblasts promotes cell growth and metastasis of breast cancer. Oncotarget 2017;8:39559-39570.

63 Xiao G, Wang X, Wang J, Zu L, Cheng G, Hao M, Sun X, Xue Y, Lu J, Wang J: CXCL16/CXCR6 chemokine signaling mediates breast cancer progression by pERK1/2-dependent mechanisms. Oncotarget 2015;6:14165-14178.

64 Allaoui R, Bergenfelz C, Mohlin S, Hagerling C, Salari K, Werb Z, Anderson RL, Ethier SP, Jirstrom K, Pahlman S, Bexell D, Tahin B, Johansson ME, Larsson C, Leandersson K: Cancer-associated fibroblast-secreted CXCL16 attracts monocytes to promote stroma activation in triple-negative breast cancers. Nat Commun 2016;7:13050.

65 Matsui A, Yokoo H, Negishi Y, Endo-Takahashi Y, Chun NA, Kadouchi I, Suzuki R, Maruyama K, Aramaki Y, Semba K, Kobayashi E, Takahashi M, Murakami T: CXCL17 expression by tumor cells recruits CD11b+Gr1 high F4/80- cells and promotes tumor progression. PLoS One 2012;7:e44080. 